\title{
Da história da psiquiatria à construção de uma nova clínica: as contribuições de Rafael Huertas para os debates historiográficos
}

\author{
From the history of psychiatry to the construction of a new clinical \\ practice: the contributions of Rafael Huertas to historiographical debates
}

\author{
Daniele Corrêa Ribeiro \\ Doutoranda, Programa de Pós-graduação em História das Ciências e da Saúde/Casa de Oswaldo Cruz/Fiocruz; \\ coordenadora de História e Memória, Centro de Estudos/Instituto Municipal Nise da Silveira. \\ dannycori@yahoo.com.br
}

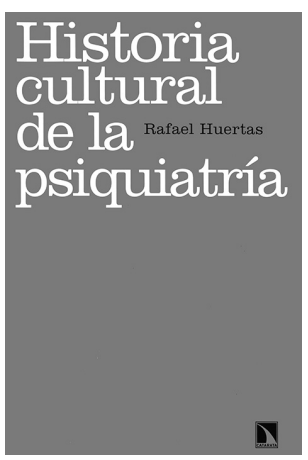

HUERTAS, Rafael. Historia cultural de la psiquiatría. Madrid: Catarata. 2012. $224 p$.
$\mathrm{D}$ esde a década de 1960, com a publicação e repercussão de História da loucura na Idade Clássica, de Michel Foucault (2010), os olhares sobre a loucura e os saberes que dela se apropriavam foram se diversificando e tornando complexos. O privilégio da narrativa médica sobre seus próprios fenômenos foi avassalado pelos mais diversos vieses, desencadeados a partir da contribuição do filósofo, trazendo à tona a ideia da loucura como produto cultural. Diante dessa abordagem, que desconstruía a naturalização da loucura como doença, abriu-se um mar de articulações teóricas e metodológicas que, apoiando as teorias foucaultianas ou questionando-as, se apropriaram da loucura como objeto, seja no campo da história, da filosofia, das demais ciências humanas ou da própria psiquiatria.

O impacto daquela e de outras obras de Foucault acabou por criar um cenário de reprodução ou de negação daquele aporte teórico. Mais recentemente, essa dicotomia vem sendo superada por meio de análises que têm retomado e problematizado os argumentos foucaultianos, ao mesmo tempo que os articulam com novas interpretações, abrangendo outros contextos temporais e geográficos. Rafael Huertas, médico psiquiatra, fundador da Red Iberoamericana de Historia de la Psiquiatría, é um dos autores que têm contribuído para esse debate. No seu livro de 2012, Historia cultural de la psiquiatría, oferece uma sistematização de algumas das correntes teórico-metodológicas que têm desenvolvido novas propostas para a historiografia da ciência psiquiátrica e de seus objetos.

Além de apresentar as análises de alguns autores e obras fundamentais para o campo, Huertas aponta uma agenda de temas, objetos, fontes e questões, demonstrando sua preocupação com a construção de saberes que possam enriquecer o debate historiográfico, mas também impactar e qualificar a clínica psiquiátrica. Ainda que a maioria das análises apresentadas diga respeito à historia da psiquiatria no contexto europeu - especialmente 
França e Espanha -, a clareza com que aborda os temas e questões relativos às obras nos permite refletir sobre a trajetória da ciência, dos seus saberes, atores e instituições no Brasil.

Segundo o próprio autor, muitas das reflexões que apresenta em Historia cultural de la psiquiatría vêm sendo por ele desenvolvidas desde 1991, quando o congresso "Penser la folie", realizado em Paris, marcava os 30 anos da publicação de História da loucura - o que aponta a importância atribuída por Huertas à obra de Foucault. No entanto, apesar de reconhecer as inovações da literatura crítica inaugurada pelo pensamento do filósofo, em contraposição à historiografia memorialística, escrita pelos próprios psiquiatras que destacavam seus feitos, Huertas enfatiza o comprometimento ideológico de ambas as vertentes. Para ele, tanto os médicos que vangloriavam a evolução de sua própria ciência quanto os novos historiadores, que denunciavam os vínculos entre a produção científica e os preceitos culturais e morais de determinada época, incorriam em erros metodológicos, justamente por não esclarecer seus objetivos e comprometimentos, já que considera impossível anulá-los. Nesse sentido, Huertas defende que os objetivos de cada autor sejam sempre muito claros e explicitados nas obras e segue a análise das várias vertentes.

No primeiro capítulo, Huertas analisa as abordagens foucaultianas, a partir da produção do próprio filósofo, mas também de um dos seus principais seguidores, Robert Castel. Essas interpretações teriam sido marcadas pelo enfoque nos discursos de ordem e controle social. Para ele, a principal questão desses e de outros autores naquele contexto ${ }^{1}$ era o controle social. A loucura teria ganhado destaque justamente por ser o resíduo do que não se enquadrava nas sociedades liberais, desde o fim do Antigo Regime.

Rafael Huertas apresenta, então, muitas das críticas dirigidas a esse enfoque teórico, especialmente as voltadas para a centralidade do poder atribuído aos médicos psiquiatras. Além de apontar as fragilidades empíricas dessas abordagens foucaultianas, destaca a necessidade de um maior investimento na pesquisa sobre a resistência que se estabelecia em relação a esse poder e sobre os interesses diversos, incluídos os profissionais, que moviam esses atores sociais.

Duas críticas nos parecem, no entanto, mais relevantes nesse capítulo. A primeira delas diz respeito ao pilar científico das instituições psiquiátricas, negligenciado por Foucault e Castel. Em relação ao caso brasileiro, na perspectiva de uma revisão historiográfica, Gonçalves (2010) apresentou o modo como os médicos da corte do Rio de Janeiro tinham a preocupação frequente com o papel terapêutico e curativo do Hospício de Pedro II. A autora demonstra que, apesar de entraves, a reivindicação do papel terapêutico e científico da instituição sempre esteve em pauta nos debates médicos.

Outro aspecto que merece destaque está relacionado ao poder psiquiátrico. Apesar de criticar a visão mais geral da abordagem foucaultiana, que enxerga um poder médico estabelecido, com objetivo claro de dominação, Huertas enfatiza as matizações elaboradas pelo próprio Foucault. Aponta, então, os momentos da obra do filósofo em que o poder aparece de forma mais fluida, como uma rede de relações. Nessa rede de relações, sobressai a ideia de subjetivação da norma, já trabalhada por Huertas (2009), dando conta de como os pacientes pactuavam e corroboravam determinadas normas. Em dissertação de mestrado, trabalhamos essa perspectiva em relação à participação das famílias nas internações no Hospício de Pedro II, buscando dar conta da apropriação que a sociedade fazia daquele espaço (Ribeiro, 2012). 
Já no segundo capítulo, Rafael Huertas trata de uma das principais releituras do contexto francês fora do viés foucaultiano, principalmente a partir das análises de Marcel Gauchet e Gladys Swain. Segundo Huertas, nesse caso, a quebra teórica em relação à literatura foucaultiana é justamente explorar um projeto terapêutico ou, ao menos, de conhecimento do subjetivo, que teria permeado a construção do pensamento psiquiátrico. Assim, demonstra como, por detrás da medicalização das paixões, do exercício de um determinado controle e das estratégias disciplinares, estava em voga uma preocupação com o sujeito da loucura.

Huertas nos apresenta detalhadamente o debate entre Gladys Swain e Foucault, apontando suas contribuições para a historiografia. Para o autor, a lente lançada sobre a subjetividade proporcionou outro panorama para a história francesa, opondo-se, pelo menos nas conclusões mais gerais, à tese foucaultiana. Se, para o filósofo, o mito fundador do alienismo teria justamente significado uma libertação para a posterior exclusão social, Swain demonstra como o pensamento pineliano inaugura uma nova concepção de indivíduo, a partir do momento em que o louco deixa de ser visto como "o outro" e passa a constituir o próprio eu moderno. Essa visão está relacionada à perspectiva defendida por Pinel de uma parcialidade da loucura, que contava com um "resto" de razão e seria, portanto, passível de cura. O debate brasileiro com essa perspectiva se apresenta nos trabalhos de Duarte (1986, p.57) e de Venancio (1993, p.123-124)

Esse viés analítico traz também uma nova visão sobre as instituições psiquiátricas e o tratamento moral. Para Swain, citado no livro aqui resenhado, o asilo, por meio do tratamento moral, objetivava a "reconstrução da individualidade do sujeito", justamente pelo que lhe sobrara de racionalidade (p.56). Tanto nessa abordagem quanto nas críticas de Huertas à perspectiva foucaultiana, o que podemos destacar é uma tentativa de reconstruir o pensamento psiquiátrico, buscando entender em seus próprios meandros, o projeto terapêutico que estava sendo defendido.

A terceira linha teórica abordada por Rafael Huertas estaria diretamente relacionada à superação do debate internalismo x externalismo na história e na sociologia das ciências. Embora já fosse problematizada por autores como Nietzsche e Foucault, a ideia da verdade científica como convenção e contingência ganhou força com o Programa Forte em Sociologia das Ciências, representado pelas obras de Steven Shapin (1999), David Bloor e Barry Barnes. À medida que as normas universais são questionadas como padrões puros da produção científica, emergem aspectos de foro social, cultural e, principalmente, profissional, que ganham relevo nesse viés analítico.

A contribuição de Jan Goldstein sobre as políticas de patronagem na consolidação profissional do alienismo francês é uma das mais enfatizados por Huertas. A patronagem configuraria estruturas informais nas quais um profissional de reconhecida projeção na comunidade científica se torna defensor de discípulos que, em troca, disseminariam suas ideias, sendo, portanto, decisiva para o sucesso ou fracasso das teorias científicas (p.76). Essa abordagem é relevante como agenda teórica posto que aponta a importância de círculos sociais e interesses profissionais para a produção científica. O destaque a esse tipo de interesse faz ainda mais complexa a análise sobre as teorias e interpretações científicas que se tornam consensuais em determinados contextos. Ian Dowbiggin, segundo Huertas, teria demonstrado, por exemplo, como as teorias hereditárias foram imprescindíveis para a legitimação profissional 
em um momento de crise de legitimidade dos manicômios, uma vez que remetiam o fracasso à incurabilidade da loucura.

Esse tipo de abordagem nos parece relevante e merece destaque especial para as análises sobre a construção do Hospício de Pedro II e a consolidação da psiquiatria no Brasil. Embora a ideia de patronagem, em Goldstein, apareça mais relacionada aos círculos científicos, trazer os interesses profissionais para o debate pode ser interessante, especialmente se articulados a outros círculos sociais. Como alguns autores têm analisado (Engel, 2001; Meyer, 2010; Ribeiro, 2012; Teixeira, 2012), o Hospício de Pedro II tem uma carga simbólica bastante expressiva em relação ao seu vínculo com a corte imperial e a Irmandade da Misericórdia. Parece-nos que o entrecruzamento dos círculos científicos, caritativos e senhoriais da corte teve papel definitivo na consolidação daquela instituição e do saber psiquiátrico ao longo da segunda metade do século XIX.

No quarto capítulo, Huertas elabora uma análise sobre o construtivismo e a ideia da loucura como construção social. Embora esse aspecto já aparecesse em Foucault e alguns de seus contemporâneos e também tangencie o questionamento sobre a verdade científica, o autor trata mais especificamente da elaboração dos diagnósticos. Primeiro, ele apresenta Charles Rosenberg (1977) e sua teoria do enquadramento das doenças, na qual são tratadas como acontecimentos biológicos, mas também como repertórios de construções verbais que refletem o contexto social e cultural em que os diagnósticos são elaborados.

No entanto, o grande avanço em termos de possibilidades de análise, segundo Huertas, está na abordagem de Ian Hacking e sua aproximação com as teorias de rotulação. A novidade aqui seria a ultrapassagem do estudo dos diagnósticos, conforme proposto por Rosenberg, para estudar-se o impacto que as classificações e nomeações das doenças promovem sobre os indivíduos. O making of people de Hacking busca dar conta do processo de constituição de uma nova classe de indivíduos, a partir do momento em que um grupo é diagnosticado (rotulado). Ao mesmo tempo, a nova classe de indivíduos interagiria com a produção do conhecimento sobre si, por meio do looping effect, ou efeito looping. O destaque para esse aspecto interativo entre especialista, diagnóstico e rotulado, enfatizando a violência dos diagnósticos e da estigmatização da loucura, é a contribuição crucial dessa linha de trabalho.

Em seguida, no capítulo cinco, o autor trata basicamente da proposta de história conceitual da psiquiatria, elaborada por Germán Berrios, corroborando a importância desse tipo de abordagem para transformações na clínica psiquiátrica atual. Depois de apresentar um histórico da psicopatologia descritiva no século XIX, Huertas corrobora a argumentação de Berrios de que, nos dias atuais, haveria certa degradação das construções teóricas por parte da clínica psiquiátrica, que estaria rigidamente vinculada a classificações impostas por manuais e compilações de diagnósticos.

Na agenda metodológica da história conceitual, a análise das teorias descritivas das psicopatologias deveria estar articulada e complementando as análises de filósofos, sociólogos e historiadores. Berrios critica a postura de muitos dos cientistas sociais pelo fato de eles se apropriarem da loucura sem se aprofundarem nas questões conceituais a ela relacionadas. Embora não apareça explicitamente na análise de Huertas, o enfoque nas questões conceituais tem sido explorado por autores da história de outras ciências, como pelo próprio Bruno Latour, citado em outros capítulos. 
A proposta de articular conteúdo científico e "ruído de fundo", como chama Berrios, é uma das grandes bandeiras dos dois autores. Para eles, essa aproximação nos estudos históricos seria a chave para trazer as mesmas reflexões para o presente. A partir do diálogo entre psiquiatras e historiadores sobre os conceitos psicopatológicos do passado, seria possível estimular o aprofundamento e a reflexão teórica entre os estudantes de psiquiatria. A proposta de Berrios e Huertas se apresenta promissora, mas também corre o risco de retomar o debate internalismo/externalismo que parece presente na ideia do "ruído de fundo", de Berrios, conforme apresentada por Huertas: como se existisse algo de universal e puro na ciência, mas que estaria sujeito a deturpações por fatores externos. Em perspectivas mais recentes da história das ciências, incluindo outras apresentadas no mesmo livro, fica claro que não existe um ruído de fundo, mas que o contexto social e cultural é totalmente decisivo na conformação dos próprios pressupostos científicos, que, por sua vez, também conformam o mundo.

Com relação à história da psiquiatria no Brasil, Facchinetti (2010) dialoga com essa bandeira ao reunir uma série de análises históricas sobre diagnósticos debatidos por psiquiatras brasileiros nas primeiras décadas do século XX. Adotando suportes teóricos diferenciados, os trabalhos escritos por historiadores, antropólogos, psiquiatras e psicanalistas analisam conceitos científicos observando-os na sociedade; a sociedade certamente podendo ser expressa de diferentes formas: ela pode ser as posições políticas e de prestígio social adotadas pelos médicos em questão, exatamente devido à importância desses atores na conformação de uma elite com projetos para a nação brasileira; pode ser também as representações sociais sobre o humano e sobre o estatuto de seus estados físico, mental e moral; ou pode estar expressa nos mecanismos de controle coletivo.

No capítulo seis, Huertas apresenta a relação entre a exploração de fontes documentais relativamente inéditas, que são as histórias clínicas de internos, e as diversas abordagens teóricas delas decorrentes. O autor demonstra como histórias clínicas, livros de registro, além de cartas e outros documentos que muitas vezes são encontrados junto desses registros, e outras fontes que deem conta do cotidiano das instituições psiquiátricas, podem contribuir para a construção de novas questões. Para ele, os primeiros trabalhos com esse tipo de material já apontam perspectivas interessantes para pensar a diferença entre o que os médicos defendiam em seus tratados e artigos científicos e o que era executável na prática.

O mais interessante da análise de Huertas nesse capítulo é a diversidade de possibilidades que ele apresenta em relação às fontes. A primeira grande chave interpretativa seria a da história vista de baixo, justamente pela polifonia desse corpus documental, que daria conta da vida cotidiana e de diversos atores sociais, e não apenas dos teóricos mais renomados da psiquiatria. Por conta dos dados seriados que podem ser mapeados, os registros clínicos são apontados como ferramentas interessantes também para estudos demográficos e para a história social. Podem ser valiosos também para a chave do controle social, além dos estudos de gênero.

Mesmo para a história conceitual da psiquiatria, o registro seriado de diagnósticos e as transformações nos modelos das histórias clínicas aparecem como aspectos inovadores nos estudos sobre os pressupostos teóricos. Por meio da análise em recortes temporais mais longos, seria possível mapear importantes transformações, tanto das classificações diagnósticas quanto da terapêutica posta em prática. 
Ainda em relação às fontes clínicas, Huertas destaca o viés consagrado por Roy Porter, que aborda o ponto de vista dos pacientes. Para esses autores, essas fontes são inovadoras por permitir, direta (cartas ou narrativas transcritas) ou indiretamente (pela fala do médico), abordar a visão do louco sobre a loucura e a sua própria experiência no manicômio. Assim, entrando no cotidiano da instituição, seria possível enxergar os pacientes e suas famílias, até então silenciados pela fala da autoridade médica.

No Brasil, as abordagens com esse tipo de material têm se ampliado consideravelmente, contribuindo muito para a historiografia. Maria Clementina Pereira Cunha (1986) inaugurou esse projeto teórico-metodológico, fazendo uma história social do Hospício do Juqueri, justamente amplificando a fala e o olhar do louco. Mais recentemente, temos tentado explorar os arquivos médicos do Hospício de Pedro II e reconstruir o perfil dos alienados, além de mapear as redes sociais que eram ali manejadas (Ribeiro, 2012). Cassília (2011) utilizou as fontes clínicas da antiga Colônia Juliano Moreira para demonstrar o modo como pacientes daquela instituição pensavam sua própria loucura e sua internação a partir da sociedade em que viviam. Wadi (2006) reconstruiu trajetórias de vida com a documentação do Hospício São Pedro. Lorenzo (2007) mapeou aspectos do controle social com base nos livros de entrada da Santa Casa de Misericórdia do Rio Grande do Sul. Muitas outras pesquisas têm usado esse material como fonte acessória.

Concordamos aqui com Rafael Huertas em relação aos problemas metodológicos encontrados para o trabalho com esse tipo de material, especialmente em relação às condições de preservação e organização. No entanto, pelo menos no Rio de Janeiro, temos assistido a iniciativas interessantes, mas ainda lentas, de preservação dessa memória.

No sétimo e último capítulo, Rafael Huertas apresenta um compêndio das contribuições analisadas anteriormente, propondo sua questão-chave, que é a articulação entre história da psiquiatria e clínica psiquiátrica. O grande fio condutor da obra de Huertas é a preocupação com a construção de um novo modelo de clínica, cuja solução passe pela pesquisa histórica. Segundo ele, a clínica vem se conformando como mera reprodutora de práticas, das quais está ausente a reflexão teórica e, logo, o conhecimento das várias determinações sociais, culturais, históricas e biológicas ali implicadas.

Para Huertas, a necessidade exponencial dessa reflexão estaria relacionada à frágil objetividade dessa ciência e, especialmente ao objeto incerto, que é o ser humano e suas condutas. Esse fator tornaria a psiquiatria mais vulnerável às condições políticas, sociais e econômicas. Se mesmo os estudos históricos das ciências chamadas "duras" têm demonstrado essa vulnerabilidade, de fato, talvez essa seja uma preocupação ainda maior, tendo em vista a complexidade do objeto.

Apesar de defender essa agenda de pesquisa, o autor de Historia cultural de la psiquiatría ressalta os problemas metodológicos dela decorrentes, especialmente aqueles relacionados ao risco do anacronismo, uma vez que defende o passado como ferramenta de transformação do presente. No entanto, ele sustenta que existiriam dois tipos de anacronismo. O primeiro deles, que seria totalmente prejudicial, é julgar a ciência do passado partindo das categorias do presente. Já o outro anacronismo, do qual não poderíamos fugir, ele relaciona ao anacronismo estrutural de Marc Bloch, já que sempre analisaremos o passado imbuídos do universo mental do presente. 
Nesse sentido, Huertas defende uma teoria da prática, ou seja, que o olhar para o passado seja feito a partir de perguntas do presente, mas que isso sirva para dotar a prática de um aporte teórico que seja transformador. Ainda que, de certa maneira, esse utilitarismo possa ser visto com certa estranheza por nós, historiadores, não podemos deixar de concordar com o autor quando defende que esses objetivos estejam claros. E, nesse quesito, Huertas não deixa a desejar, apresentando com bastante clareza o seu projeto. Aliás, o próprio autor destaca que os objetivos de médicos e historiadores sempre serão diferentes, justamente pelo universo mental em que estão inseridos. No entanto, é inegável que a interação dinâmica entre historiadores e psiquiatras, por ele defendida, tem belíssimos frutos a gerar.

A obra de Rafael Huertas tem muito a contribuir para os historiadores e para os clínicos em formação. Para os primeiros, os vieses teóricos e metodológicos didaticamente apresentados são uma importante e facilitadora porta de entrada nos estudos sobre a história da psiquiatria. Para os clínicos, o livro pode ser ponto de partida para as muitas reflexões propostas por Huertas. Os exemplos perfeitamente escolhidos, tanto para demonstração dos autores quanto para seus questionamentos e proposições, transitando entre quase dois séculos de história, abrem um mar de possibilidades para quem quer que se interesse pelas temáticas da mente.

\section{NOTA}

${ }^{1}$ Robert Nye (2003) também comenta a relação entre esse tipo de abordagem e a esfera política e cultural contestatória dos anos 1960-1970.

\section{REFERÊNCIAS}

CASSÍlIA, Janis.

Doença mental e Estado Novo: a loucura de um tempo. Dissertação (Mestrado em História das Ciências e da Saúde) - Fundação Oswaldo Cruz, Rio de Janeiro. 2011.

CUNHA, Maria Clementina P.

O espelho do mundo: Juquery, a história de um asilo. Rio de Janeiro: Paz e Terra. 1986.

DUARTE, Luiz Fernando Dias.

Da vida nervosa nas classes trabalhadoras urbanas. Rio de Janeiro: Jorge Zahar. 1986.

ENGEL, Magali Gouveia.

Os delírios da razão: médicos, loucos e hospícios (Rio de Janeiro, 1830-1930). Rio de Janeiro: Editora Fiocruz. 2001.

FACCHINETTI, Cristiana (Ed. convidada). História, Ciências, Saúde - Manguinhos (Hospício e psiquiatria na Primeira República: diagnósticos em perspectiva histórica), v.17, supl.2. 2010.

FOUCAULT, Michel.

História da loucura na Idade Clássica. São Paulo: Perspectiva. 2010.

GONÇALVES, Monique de $\mathrm{S}$.

Mente sã, corpo são: disputas, debates e discursos médicos na busca pela cura das "nevroses" e da loucura na Corte Imperial (1850-1880). Tese (Doutorado em História das Ciências e da Saúde) - Fundação Oswaldo Cruz, Rio de Janeiro. 2010.

HUERTAS, Rafael.

Medicina social, control social y políticas del cuerpo: la subjetivación de la norma. In: Miranda, Maria; Sierra, Álvaro. Cuerpo, biopolítica y control social: América Latina y Europa en los siglos XIX y XX. Buenos Aires: Siglo XXI. p.1941. 2009.

LORENZO, Ricardo de.

"E aqui enloqueceo": a alienação mental na Porto Alegre escravista (c.1843-c.1972). Dissertação (Mestrado) - Universidade Federal do Rio Grande do Sul, Porto Alegre. 2007.

MEYER, Manuella.

Sanity in the South Atlantic: the mythos of Philippe Pinel and the asylum movement in nineteenth-century Rio de Janeiro. Atlantic Studies, v.7, n.4, p.473-492. 2010.

NYE, Robert A.

The evolution of the concept of medicalization in the late twentieth century. Journal of History of the Behavioral Sciences, v.39, n.2, p.115-129. 2003.

RIBEIRO, Daniele C.

O Hospício de Pedro II e seus internos no ocaso 
do Império: desvendando novos significados. Dissertação (Mestrado em História das Ciências e da Saúde) - Fundação Oswaldo Cruz, Rio de Janeiro. 2012.

ROSENBERG, Charles E.

Framing disease: illness, society and history. In: Rosenberg, Charles E.; Golden, Janet (Ed.). Framing disease: studies in cultural history. New Brunswick; New Lersey: Rutgers University Press. p.XIII-XVI. 1977.

SHAPIN, Steven.

A revolução científica. Lisboa: Difel. 1999.

TEIXEIRA, Manoel Olavo Loureiro.

As origens do alienismo no Brasil: dois artigos pioneiros sobre o Hospício de Pedro II. Revista Latinoamericana de Psicopatologia Fundamental, v.15, n.2, p.364-381. 2012.

VENANCIO, Ana Teresa A.

A construção social da pessoa e a psiquiatria: do alienismo à nova psiquiatria. Physis: Revista de Saúde Coletiva, v.3, n.2, p.117-135. 1993.

WADI, Yonissa Marmitt.

Experiências de vida, experiências de loucura: algumas histórias sobre mulheres internas no Hospício São Pedro (Porto Alegre/RS, 1884-1923). História Unisinos, v.10, n.1, p.65-79. 2006. 